\title{
CAUSES OF ANGER IN M. IRFAN HIDAYATULLAH'S NOVEL CERMIN RETAK: TABIR ROBBI DAN ROBBANI
}

\author{
Iswandi, M. Manugeren, Purwarno Purwarno \\ Faculty of Literature, Universitas Islam Sumatera Utara, \\ Medan, Indonesia \\ e-mail: ars.isda2019@gmail.com
}

\begin{abstract}
This study is concerned with the causes of anger. Anger a basic human emotion, as elemental as, gladness, sadness, anxiety or disgust. These emotions are tied to basic survival and are honed over the course of human history. Anger is related to the "fight, flight, or freeze" response of the sympathetic nervous system: it prepares humans to fight. But fighting does not necessarily mean throwing punches; it might motivate communities to combat injustice by changing laws or enforcing new behavioral norms. This is the positive trait of anger though in many cases only the negative ones are seen. Everyone experiences anger at some point. It becomes problematic, however, when the frequency or severity of anger interferes with relationships, work performance, legal standing, or mental health. All these points are faced by the main characters of the novel. The whole research is done by means of descriptive qualitative research, exposing the social features, in this case anger. The research results show that there are causes of anger found through the study: past experience and lack of problem-solving ability. Owing to traumatic past experiences, one of the main characters does a kidnapping and on the second point, the inability of solving problems, makes another main character filled with anger.
\end{abstract}

Keywords: anger, experience, problem solving

\section{Introduction}

The subject matter which will be analyzed in this writing is concerned with causes of anger in the novel Cermin Retak: Tabir Robbi dan Robbani, written by an Indonesian writer, M. Irfan Hidayatullah and published in 2005, focused on two points of discussion past experience and lack of problem-solving ability. Anger constitutes a powerful emotion and if it is not handled appropriately, it may have destructive results for you and those closest to you. Uncontrolled anger can lead to arguments, physical fights, physical abuse, and assault and self-harm.

Anger is something which commonly happens in the life of human beings. This means that through a novel, a genre in literature, one could learn things about life. Literature and life both talk about people and society. For literature, society is the most important factor; while society is a vital object for social science. All these things affect each 
other's attitude and movement. When literature has put forth something right in its creation, it will in turn affect social attitudes as sociality grows (Manugeren and Hidayati: 2018).

And there must be the reasons or causes why people get angry and there must also be the effects or consequences that can happen. According to Videbeck (2006: 25), anger which is also known as wrath or rage, is an intense emotional state involving a strong uncomfortable and hostile response to a perceived provocation, hurt or threat.

Modern psychologists view anger as a normal, natural, and mature emotion experienced by virtually all humans at times, and as something that has functional value for survival. Uncontrolled anger can, however, negatively affect personal or social wellbeing and impact negatively on those around them. While many philosophers and writers have warned against the spontaneous and uncontrolled fits of anger, there has been disagreement over the intrinsic value of anger. The issue of dealing with anger has been written about since the times of the earliest philosophers, but modern psychologists, in contrast to earlier writers, have also pointed out the possible harmful effects of suppressing anger (Kempt \& Strongman, 1995: 397)

The novel tells about the causes of anger experienced by some main characters of the novel. Jaka, one of the main characters of the novel, experiences something which really cannot be forgotten as well as his wife, Khairunnisa. It is also an experience which has made him and his wife very anxious, sad, and very angry. It is because his son, Ahmad Robbani, who is still very young, about one year old, is kidnapped. A few years later, it is known that the kidnaper is a Chinese man named Hans, and he names the child he has kidnapped as Robbi.

Since the kidnapping of his son, Jaka has felt very sad and anxious. He keeps on trying to search for his son. He even asks policemen to help him to find his son; nevertheless, the policemen report him later that they have not been successful to find his son. Then he does not know what he must do. When he thinks about the cruel deed of anyone who has kidnapped his son, soon he becomes very angry. He is even easy to get angry with anybody else who does something which he thinks makes his heart not feel nice. He remains to be a man who is very sensitive up to his second son Ahmad Robbani was born. The loss of his first son makes him anxious or restless. He never gets information about the existence of his son anymore for several years. Meanwhile, Hans, the name of the man who has kidnapped the child, has already adopted him to be his son. Finally, however, after several years, Jaka can meet his first son again and he is not a small boy anymore. He has grown up to become a young man who is called Robbi whose face is the same as the face of Ahmad Robbani, the first son of Jaka.

It is also told in the story that before Jaka gets married with Khairunnisa, exactly when he is a teenager, he has a bad behavior. He is bad and stubborn. He does not hesitate to hit those who underestimate him. As a high school student, he is disliked by many of his friends, especially those who like a beautiful female student whom he likes and loves. They do not dare to approach her because he will be angry and hit them. He even dares to spit the face of one of his teachers because of having punished him. He even dares to kill someone whom he dislikes, but he is not arrested because the police do not know the doer of the murder. He keeps trying to get the heart of Khairunnisa, the beautiful schoolgirl friend, but the girl shows no reaction that she likes him. Near the end of his school, he is rarely seen until the final school exam.

At the school farewell program, he comes and donates a song and recites a poem to Khairunnisa, the girl with whom he has fallen in love. From then on, she begins to like him, but because she does not say anything that she likes him, he then leaves her 
and the room of the party. Then she never sees him anymore. When she gets the news about him, he is already treated at a rehabilitation home for drug addiction. He has even experienced suspended animation that really torments him.

\section{Literature Review}

\subsection{Anger}

Anger, the vehement passion, is universal. Anger is found everywhere on earth and is known to every individual who has ever lived. Even the gods get angry. However, anger's moral status is perennially contested. Some say anger can be a virtue, others that it is always a vice. According to its fans, anger is a refined detector of injustice and uniquely effective at getting oppressors to yield their evil ways. Opponents of anger say that anger is undisciplined and sloppy (Cherry \& Flanagan, 2018: vii).

There is a scientific consensus that the disposition to anger is a biological adaptation in the standard sense that it enhanced fitness in ancestral species at the time it evolved, and is gifted in some modified form to modern Homo sapiens. A disposition to anger keyed first and foremost to threats to food, mates, children, and close kin is nature's solution to a particular sort of fitness problem. The disposition is now part of human nature.

Darwin (1998) hypothesized that humans evolved to more or less automatically express the intersection of the somatic, phenomenal, and behavioral properties of anger and the other basic emotions on our faces. An angry face can signal how someone feels and what they intend to do in time for someone else to stop doing what they interpret as a fitness threat before they take hostile action. In this way, others can see that we are angry and respond appropriately. Anger in response to a threat both communicates that there will be hell to pay if the other does not stand down and efficiently motivates or sustains motivation for hostile action on the part of the angry individual if it is necessary.

Knowing that some sort of disposition to anger is an adaptation also does not settle whether and to what degree the disposition can be controlled, moderated, modified, suppressed, or sublimated by individual will, education, self-cultivation, culture, or the moral and political order. We do not know how much individual variation there is in the disposition to anger and whether, and if so how, the settings might be gendered (Panksepp and Biven: 2012). These are questions for neuroscience and psychology. What is settled is that there is some sort of core disposition to anger that is universal and it evolved because it had ties to fitness. If reasons of fitness are acceptable as justifying reasons for anger at some times and in some situations, for example, in self-defense, then there might be such reasons for some kinds of anger.

When scientists speak of anger, there are similar complexities. Sometimes "anger" is used to name some pre-linguistic phenomenal or affective core, the minimal what-it-is-like-to-be-angry quake, possibly shared across mammals (Panksepp and Biven 2012). In social or cultural psychology, anger typically names a functional syndrome, a normative script, which involves the causes, mental states, somatic feels, and types of actions, dubbed "anger" in a particular society or culture. Philosophers are primarily interested in the cognitive aspects of anger, in what the anger is about, and whether there are good reasons to experience it and act on it.

Anger can be triggered directly, as when harsh words, meanness, cruelty, disloyalty, ordishonesty make one angry, or indirectly, as when anger percolates out of a mix of other emotions such as envy, jealousy, fear, shame, or guilt. Anger can be 
directed at any physical object or event that blocks one's way. It can be directed at oneself, one's pets, friends, loved ones, anonymous others, groups of individuals; at laws, regulations, social policies, political institutions; and at the impersonal heavens.

Social construction views try to explain the fact that anger as described and enacted across cultures is a motley, a heterogeneous set of reactions to things we do not like that lie a very long distance from the core survival circuitry. What anger is nowadays requires concepts, culture, and language. It is extended and governed by social norms, and sits inside various systems of practices. Anger is among the things we do, not simply an emotion or passion we have or possess. It is a cultured passion, a participant in modern normative orders, governed by complex psychosocial norms that provide scripts and permissions for what appropriately triggers anger, what warrants it, and what behaviors are acceptable when angry. There are age, gender, status, role, and occupation norms that govern permissions for who can be angry, why, how much, to what effect, as well as permissions and norms governing acceptable responses to anger.

The two main kinds of social constructionism differ mostly in terms of how they conceive the nature of the core disposition that modern forms of anger are built on. The first kind links the disposition to anger with a set of learning mechanisms that allow core anger to be extended to novel things. What the core form is extended to-bad manners, slights, and racism - is a matter of culture (Panksepp and Biven: 2012). The second social constructionist view denies that there are any interesting core emotions with well-defined neural, phenomenal, somatic, or facial fingerprints (Russell: 1994). There is a range of valence organismic states (these are called "dimensional theories"), positive/negative, disturbed, perturbed, serene, intense - that are then interpreted by a culture, which also assigns norms for initiating episodes of anger, rules of engagement in such episodes, and so on. Anger might have no distinctive neural finger-print, nor even a common core phenomenal feel until we interpret and classify the way(s) we are feeling, perhaps some general or inchoate anxiety or distress along with a disposition to respond negatively, as anger (Barrett 2017).

Anger's functional roles and moral status show huge variation and cultural scripting. One ought never to experience anger or act on it. Besides, they believe anger can be transcended (Shweder et al.: 2008). There are several important lessons. First, this very partial inventory of cross-cultural scripts for anger reveals some of the possibility space actually explored and enacted in living human communities. Since whatever is actual is possible, we, for any "we," could do anger differently than we now do it, if we had reasons to do so, were socialized differently, and so on.

The original disposition to anger is malleable. It can be molded by social norms. It is penetrable by culture, possibly even by individual willpower and selfcultivation. Secondly, it is possible that each tradition mentioned earlier that approves of anger (not all of them do) would avow an Aristotelian view to the effect that warranted anger should not be excessive or defective. Nevertheless, this would not shed any light at all on the content of their anger norms. Typically, one is asking whether some instance or kind of anger is aligned with high-minded norms, "our" best thinking about anger.

\subsection{Spheres of Anger}

There are spheres of anger. They are (1) personal: anger at family and friends

(2) communal: anger in wider communal and commercial relations, and (3) political: anger at policies and institutions of government. One might think that there are different 
rules for anger in each domain. Anger among family and friends is warranted especially where there is inconsiderateness, disloyalty, failure to pitch in as expected, and betrayal; in commercial relations when there is rudeness, trickery, scheming, contractual failure; and in politics when there is injustice. Various norms govern how one can appropriately express anger in each sphere, for example, by harsh words or lawsuits.

Then, there are types of anger. These include (1) payback anger where someone intends to cause another physical or mental pain and suffering, and/or status harm, typically because somebody else caused him or her pain (2)pain-passing anger where someone intends to cause pain to another because he or she is in pain(3)instrumental anger where someoneis angry withsomebody else and express it with the aim to get him or her to behave, apologize, or fix things, but not mainly to cause him or her to suffer (4)recognition respect anger where someone does not wish for payback. He or she has been diminished and demands recognition respect as a way of restoring a sense of his or her self-worth and as a signal that somebody else is not the callous kind of person he or she just seemed to be(5) feigned, "as if," anger where someone is not really angry or very angry in the inner phenomenal sense but use "angry words" or threats to gain compliance (6)political or institutional anger at social policies or laws or structures that are unfair, racist, sexist, or otherwise harmful or dehumanizing, and (7)impersonal anger that expresses horror and fury at the heavens, nature, human evil, or folly. Keep your eyes on the first two kinds of anger, payback and pain-passing anger. These are the two varieties that are generally viewed as the most problematic morally. If these two kinds are not good, but the other five varieties are often acceptable, we will still have reason to be watchful that the aims of pain-passing and payback do not poison the good intentions behind many forms of instrumental, recognition respect, and political or institutional anger. What makes the pain-passing and payback kinds of anger bad is that their primary aim is to hurt another individual (Nussbaum 2015: 51).

Anger is all too human. Contemporary psychology classifies anger as an emotion. It is thought that anger harkens back to our evolutionary fight or flight mechanism. While fear engenders the visceral physiological response to perceived threat that prompts us to flee, anger denotes that visceral physiological response to perceived threat that prompts us to confront, to resist, and to counter. In philosophy (especially moral psychology), much work has been done to offer evaluative accounts of anger. Some argue that anger is always negative or destructive, something to be suppressed or eschewed. Others question whether we have an obligation, a moral duty, to get angry or indignant when met with undue injury (Nussbaum 2015: 51).

Nussbaum lays out two paths of anger. The first is the path of status. The injury is taken as an unjust humiliation, slight, or down-ranking, reducing the event to a concern about the angry person's rank or status. The angry person is portrayed as anxious and obsessively focused on protecting his or her honor. To right the injury, it is thought that the status of the angry person should be raised and the status of the offender lowered-a reversal of positions. This focus on status, according to Nussbaum, diverts attention away from the reality of the victim's pain, the material theft, and the bodily wrong suffered. It reeks of infantile narcissism. This path places an overblown value on the relative status of the angry person, placing moral deliberation on dubious values. The path of status is thus normatively objectionable, committing what Nussbaum labels the "status error" (Nussbaum 2015: 51). The second path is the path of payback. Here the angry person focuses on retaliation. The angry child bullied on the playground imagines the infliction of retaliatory pain and humiliation on the offending children. 
Those who have been sexually assaulted (and are angry about it) imagine various scenarios where the offenders suffer extensively-expelled, imprisoned, and raped. Angry-enslaved people imagine a future in which power is attained and their bondsmen are enslaved and brutalized (Nussbaum 2015: 55). The point is that the angry person on the path of payback imagines that the offender's suffering would actually make things better and that it would somehow assuage the damages. Nussbaum argues that this line of thought engages in magical thinking. Acts of retaliation do not right the cosmic balance; they do not produce justice. Anger is rendered "a central threat to decent human interactions" (Nussbaum 2015: 41). It is an irrational and destructive vestige of human prehistory, which forward-looking systems of justice have, to a great extent, made unnecessary.

Nussbaum has articulated an indictment of garden-variety anger. The paths of status and payback are normative irrationality. Anger is primitive, destructive, and no longer necessary for the pursuance of justice. Nussbaum's paper ends with this sentiment. Yet there is one exception, one subspecies of anger that seems to escape Nussbaum's reproach. There is a third path: the path of future welfare (Nussbaum: 2015). On this path, anger "quickly puts itself out of business" and transitions into concern for those actions that tend to augment the welfare of those parties whose interests are in question.

Anger, in rational people, will quickly "laugh at itself" and go away. Anger is dispelled for saner thoughts, and residual concerns for punishment are enveloped in the larger goal of improving offenders and society (Nussbaum: 2015). Anger will then take on a new appearance; it will resemble something like "compassionate hope." Nussbaum labels this healthy segue into forward-looking thoughts of welfare, this movement from anger to compassionate hope, "the transition". To explicate the transition, Nussbaum evokes Martin Luther King Jr., providing a brief analysis of the "I Have a Dream" speech. She points out that King begins with "an Aristotelian summons to anger," citing the wrongful injuries of racist oppression and the nation's failure to fulfill its implicit promises to equality (Nussbaum: 2015).

\subsection{Causes of Anger}

According to Hendricks et al (2013), clinched fists, grinding teeth, increased heart rate are the signs of an intense physical workout session or someone experiencing a heart attack or stroke. However, they are just a few of the physiological signs of someone experiencing anger. Anger is a common human emotion. It is a strong emotion often caused by some form of wrong- doing, ill-treatment, or unfairness. Anger, according to the cognitive behavior theory is attributed to several factors such as past experiences, behavior learned from others, genetic predisposition, and lack of problemsolving ability. We all experience it, some more often that we like to admit.

We get angry for reasons, or, at any rate, for what we take to be reasons. If asked "why are you angry?" you will cite something (that you think) someone did or failed to do. That action or omission is what you are angry about. Getting angry is easy to understand: by betraying your trust, for example, you will find out that it makes you angry. What is harder to understand is why you might cease to be angry. For suppose that someone offers compensation, apologize profusely, promise never to do it again, radically and convincingly transform his or her character. Feeling of anger arises due to how we interpret and react to certain situation. Everyone has their own triggersfor what makes them angry. 
Hendricks et al. (2013) then states that it is plain to see that low tolerance levels of frustration factor into both internal and external sources of anger. Recognizing these factors may help us deal with our anger and help resolve our anger issues. The four effects of anger according to him are stress/anxiety, pain physical and emotional, drugs/alcohol, and recent irritation- "having a bad day".

On the problem-solving account, anger is desire-like: It responds to reasons to make (what the agent perceives as) a positive change in the world. If the reasons to be angry are reasons to, for example, take measures that prevent future violations of the relevant kind, then they will not be eternal. Martha Nussbaum presents this as the correct account not of anger as such but of a species of anger she calls "transition anger." Others have argued that anger is an attempt to protest a threatening message, to the effect that the victim is deserving of bad treatment; to reverse the ongoing misbehavior of a wrongdoer who, in failing to apologize, acts as though the wrong were acceptable; to get the wrongdoer to understand what he or she has done; to be restored to the status from which the wrongdoing demoted one; and to secure the wrongdoer's commitment to the norm he or she violated.

\section{Research Method}

The research method used in this study constitutes the qualitative method of research. Creswell (2009) states that qualitative research is a means for exploring and understanding the meaning individuals or groups ascribe to a social or human problem. The process of research involves emerging questions and procedures, data typically collected in the participant's setting, data analysis inductively building from particulars to general themes, and the researcher making interpretations of the meaning of the data used. Qualitative research is a situated activity that locates the observer in the world. It consists of a set of interpretive, material practices that makes the world visible. These practice turn the world into a series of representations including fieldnotes, interviews, conversations, photographs, recordings and memos to the self. The data are taken from a printed material, in this case, taken from the novel and the data sources are in the forms of words, phrases, and sentences in the novel, tending to the problems of the causes of anger. This plan involves several decisions and they need not be taken in the order in which they make sense to me and the order of their presentation here. The overall decision involves which design should be used to study a topic. Informing this decision should be the worldview assumptions the researcher brings to the study, procedures of inquiry (called strategies); and specific methods of data collection, analysis, and interpretation.

\section{Results and Discussion}

\subsection{Past Experience}

Hans is a Chinese man who has kidnapped Jaka and Khairunnisa's young son in a park one evening. He brings the child who is still one year old into his house with breath- struggling. He has no idea what he has to do; moreover, the child cries all the time. He tells his wife to immediately hide the child before the police enter their house. He urges his wife called Mei to immediately do what he orders.

Mei is very surprised by what her husband is doing. She asks her husband if she is aware of what he has done. However, he does not care about her husband question. He even forces and threatens her. He tells her that the child is an indigenous child, their child who has expelled and removed them. He also tells her with emotion that they were 
considered low ranking citizens in this country. He tells her angrily that he will humiliate the child and kill him. Hans' anger because of his past experience, that is, when he is still a small boy about ten years old can be clearly illustrated through the following quotation:

"Hurry up, Mei. Hurry up and hide this son of a bitch before the police enter this house!" My husband was still breathing and his grin suddenly said: "What are you doing? Be conscious Hans, be conscious." I said at the time. However, he still forced and threatened me. "Hurry up. Otherwise, I will kill you and this child. Hurry up. Don't pretend you don't know the problem. This child is indigenous, their child who has eliminated and driven us away. Do you remember, Mei? We have been considered a lowly nation in this country. He..he.. he ... come on ... don't hesitate! I will humiliate this child. I will kill him soon." His grin made my hair stand on end. My husband has gone crazy. (Hidayatullah, 2005: 118)

As illustrated in the above quotation, it can be proved that Hans gets angry because of remembering his past experience. He remembers how they, Chinese people, are beaten, killed, and kicked out several years ago. They are even regarded as the lowly nation in this country. Those are the reasons why he is determined to kidnap the small child who is more or less one year old. The child is actually the son of Jaka and Khairunnisa and his name is Ahmad Robbani. He kidnaps him in a park when is playing there. However Jaka and Khairunnisa do not know anyone who already does it.

Hans also remembers the events when the Chinese drift happens. He sees for himself what has happened at that time. At that time he is a child, still ten years old. He just spells out the events and spells extinction. His mother is grabbed and his father is kicked. He does not know where those people come attacking. He continues to watch every inch of events. What he sees is an incident in the city of Bandung in September 1973. The incident can be described through the quotation below.

Bandung, September 1973, a mob of indigenous people burned shops. Jealousy that had been buried over the economic success of Chinese ethnic suddenly exploded. The reason is actually only a small event. It is because of the nudging of one of the natives by the car of a Chinese trader. However, that was precisely the lighters from the fire that were accidently thrown at the gasoline scattered on the streets. The Astana Anyar region was volatile. Bandung was recorded in history. Chinese ethnicity were driven out. ............................." Burn ... burn!Drive them away! Expel the infidels! Return them to their country! They think it is easy to rule here." Then they moved and houses were stoned. Glasses were broken and screams were very touching. (Hidayatullah, 2005: 12-13)

The quotation above shows that several years ago there is a very tense event in Bandung, precisely in 1973. Hans sees firsthand what has happened, including the very abusive treatment of native people towards his father and mother, the burning of a number of shops, and the expulsion of Chinese ethnic. He is actually very angry with the people who are doing that atrocity, but because he is still very small he does not dare to do anything, He could only see. 
When he grows older and after getting married with a young woman named Mei, Hans remembers again about the tense event that he ever experienced in Bandung. He could not forget what people have done to his parents. He remembers how they burn many shops in the city and how they force the people of his ethnic to leave the city where they have lived there for a long time. Then, it is reasonable for him to be very angry. To show his anger, several years later he kidnaps a small boy who is later known as Robbani, the first child of Jaka and Khairunnisa.

\subsection{Lack of Problem-Solving Ability}

Jaka has fallen in love with Khairunnisa since the first time he meets her, a girl who studies at the same school with him. He is quite handsome but he has a bad character. Because of his rude behavior to his friends and many other people, she does not like him. He is even the young man that is hated by her very much. Besides, he is feared by many people so no one dares to cause trouble with him.

He really likes her and he is brave enough to say it to her. However, he mentions it impolitely. With his cold voice, he even threats her that she cannot refuse him. In other words, he forces her to be his girlfriend, partner, and companion. He seems not to know a good way how to make a girl's heart like him and even fall in love with him. This becomes his problem. He has lack of ability to solve his problem about tempting a young woman, especially Khairunnisa, so that she can fall in love with him. This can be described in the following quotation:

"I like you, Nisa. And you can't refuse me. I'm not used to being rejected. Do you want to be my girlfriend, my partner, my companion?" his voice was cold, dank, like that alley. I have goosebumps on my hair. Bull! Geez. I am dead. My Mind. And I was silent, petrified, silent and afraid. Incidentally, there was no one in the alley. His eyes were sharp. I'm also ready to scream and ask for help, but ... "Don't try to scream. "I won't hurt you. I won't hurt women, especially you, because I like you, because I love you. I'm sure you like me too." (Hidayatullah, 2005: 34-35)

The above quotation clearly proves that Jaka has lack of ability to solve his problem in persuading Khairunnisa to be his girlfriend. He really likes and loves her. He really wants to be able to come closer to her and to be somebody who is there in her heart. He wants her to say that she also loves him. He has tried to force his will to be her boyfriend by stating that she cannot refuse him and he is not used to being rejected.

Jaka continues to approach her but she is angry with him by saying that she does not like a bad person like him. She tries to continue her steps but he stops her. He approaches her and brings his face closer to her. At this time, she is very surprised and feels scared. She imagines that she might be helpless if he raped her. She imagines that her world would be destroyed if he does it to her. His inability to make her like him can be illustrated through the quotation below.

"Huh, who would like a bad guy?" I snapped as I continued, but he stopped me. He approached me. His face approached my face. How it was like the ticking of a bomb detonator. I might not be helpless if he rapes. I will definitely not be helpless. And buиum ... My world will be ruined if he does that, but ... "I really like you. I won't hurt you. 
Instead, I'll take care of you, always," he whispered. Then he lightly welcomes me to continue the journey. (Hidayatullah, 2005: 35)

The above quotation can be meant that Jaka has not been successful to persuade Khairunnisa to be his girlfriend. He has lack of ability to make her fall in love with him. However, he keeps trying to approach her in ways she does not like. She firmly tells her that she does not like him. She frankly tells him that she does not like a bad young man like him even though he then tells her that he really likes her, will not hurt her, and will take care of her.

Jaka has tried to keep on persuading her in order that she wants to be his girlfriend. He has told her that he really loves her and he will always keep her. However, she still refuses his love to her. Her refusal really makes him disappointed. He seems to think that he has no ability to win her heart. As a result, he gets angry and he shows his anger to every young man who likes her and wants to be her boyfriend. His anger, because of his lack of ability to win the heart of the girl he loves, can be proved through the following quotation:

And sure enough, he always tries to look after me, but in an inhuman way. There are too many victims after that. Deni was found lying in the lavatory with injuries due to beatings. Kukuh came to school with a grimace and changed my attitude to me. Danang, away from me so suddenly, even frightened when I tried to contact him. In fact, I really liked him at the time. (Hidayatullah, 2005: 35)

As illustrated in the above quotation, it can be seen clearly that Jaka changes to be angry after he realizes that his effort to win her heart is not successful. He seems not to know how to make her feel safe and happy when he is near to her. He has lack of ability to make her want to be his girlfriend. Now he feels that all young men around her are those who want to persuade her. He feels that all of them are his competitors. Consequently, he is not reluctant to punch, to box, and to kick them until they are injured and none of them dares to fight him.

Jaka's anger does not end there. It is because he has just heard her words that really offend him when he asks her to come with him on his motor-bike. She does not want to be asked and does not want to go with him even though he forces her to come with him. She instead says that she has the right to refuse his invitation while he does not want to hear her reject his invitation. She snaps at him saying that he is a villain. Then she leaves and goes to take a mini-bus. Afterwards, in his anger, he chases the mini-bus and stops it. He tells the mini-bus driver to come out and then he hits him. This anger can be described as follows:

"No Way. I have the right to reject anyone who invites me. Especially you. You bad guy!" suddenly my words were so brave before him. And after that I took a mini-bus that happened to stop in front of me. He only stood up when I took the mini-bus. However, his eyes implied a grudge. And indeed, not far away, suddenly the mini-bus that took me was overtaken. The mini-bus stopped. He went down. He pulled the mini-bus driver out. He beat the driver. The driver resistance was meaningless because Banteng was indeed good at fighting. When satisfied, he said loudly, "Don't try to cause trouble with me!" he said 
while glancing at me who was gaping. Shock.Likewise the passangers who were there could not do anything. (Hidayatullah, 2005: 37)

The above quotation clearly describes that Jaka, who is often called Banteng, is very angry with Khairunnisa, especially to the driver of the mini-bus. He feels that the mini-bus driver is deliberately stopping in front of her and hauling her away. He cannot accept this reality and does not like to be treated in such away. He really feels slighted. Therefore, he chases the mini-bus and forces him down from the mini-bus and then beats him up. The driver is unable to fight him.

The anger of Jaka can actually be concluded as the form of his lack of problem solving ability, in this case his disability to come closer to Khairunnisa and persuade her to be his girlfriend. Because of his rudeness, he actually makes her afraid and does not want to be approached by him. He really has no ability to make her fall in love with him. He does not know what to do then.

\section{Conclusion}

After the analysis of the matter which is concerned with anger in M. Irfan Hidayatullah's novelCermin Retak: Tabir Robbi dan Robbani (2005), the writer of this study can give some important conclusions. The conclusions which are regarded important to be given here are as follows:

First, everyone has past experiences. There are good ones and bad ones. Good past experiences usually have good effects or consequences in the future. However, the past experience which is bad may have bad effect to anyone who has ever experienced it. He or she will possibly show their anger or do a revenge to anybody who has ever made them disappointed, hurt or suffered.

Second, because of having lack of problem-solving ability, someone can get stressed and later they can be angry. No matter what the problem is. It can be a usual problem in their daily life or activity. It can also be a special problem related to their relationship with their opposite sex; and the two points are found in the research result.

\section{References}

Barrett, Lisa Feldman. (2017). How Emotions Are Made: The Secret Life of the Brain. Boston, MA: Houghton Mifflin Harcourt.

Cherry, Myisha \& Flanagan, Owen. (2018). The Moral Psychology of Anger.London: Rowman \& Littlefield.

Creswell, John W. (2009). Research Design: Qualitative, Quantitative, and Mixed Methods Approaches. Third Edition. California: SAGE Publications, Inc.

Darwin, Charles. (1998). The Expression of the Emotions in Man and Animals.With introduction, afterward, and commentaries by Paul Ekman. $3^{\text {rd }}$ ed. New York. Oxford University Press.

Hemdricks, Lavelle et al. (2013). The Effects of Anger on the Brain and Body. Volume 2 National Forum Journal of Counseling and Addiction.

Hidayatullah, M. Irfan. (2005). Cermin Retak: Tabir Robbi dan Robbani. Bandung: Mizan Media Utama.

Kempt, Simon \& Strongman, K. T. (1995). Anger Theory and Management: A Historical Analysis. The American Journal of Psychology. Vol. 108, No. 3, pp. 397-417. 
Causes of Anger in M. Irfan Hidayatullah's Novel Cermin Retak: Tabir Robbi Dan Robbani, Iswandi, M. Manugeren, Purwarno Purwarno

Manugeren and Hidayati. (2018). Universal Concept in Literary Work through J. M. Synge's Riders to the Sea. Retrieved from The $1^{\text {st }}$ Annual International Conference on Language and Literature, KnE Social Sciences, pages 484-493. DOI 10.18502/kss.v3i4.1958

Nussbaum, Martha C. (2016). Anger and Forgiveness: Resentment, Generosity, Justice. New York: Oxford University Press.

Panksepp, Jaak \& Biven, Lucy. (2012). The Archeology of Mind: Neuroevolutionary Origins of Human Emotion. New York: Norton.

Shweder, R. A. et al. (2008). The Cultural Psychology of Emotion: Ancient and Renewed. Handbook of Emotions. $3^{\text {rd }}$ ed. eds. M. Lewis, J. M. Haviland-Jones, and L. F. Barrett. New York: Guilford Press.

Videbeck, Sheila L. (2006). Psychiatric Mental Health Nursing. Third Edition. Lippincott Williams \& Wilkin. 